\title{
ASSESSING HYDROMETEOROLOGICAL IMPACTS WITH TERRESTRIAL AND AERIAL LIDAR DATA IN MONTERREY, MEXICO
}

\author{
F.D. Yépez Rincón ${ }^{\text {a, }}$, D. F. Lozano García ${ }^{a}$, P.Vela Coiffier ${ }^{\text {a }}$, L. Rivera Rivera ${ }^{\text {a }}$ \\ ${ }^{a}$ Environmental Quality Center, ITESM, Ave. Eugenio Garza Sada 2501 Sur, Col. Tecnológico, C.P.64849 \\ Monterrey, N.L. México - \\ *fabiola.yepez@gmail.com
}

KEY WORDS: Hidrometeorological impacts, Lidar, Environmental policy, Risk Management.

\begin{abstract}
Light Detection Ranging (Lidar) is an efficient tool to gather points reflected from a terrain and store them in a xyz coordinate system, allowing the generation of 3D data sets to manage geoinformation. Translation of these coordinates, from an arbitrary system into a geographical base, makes data feasible and useful to calculate volumes and define topographic characteristics at different scales. Lidar technological advancement in topographic mapping enables the generation of highly accurate and densely sampled elevation models, which are in high demand by many industries like construction, mining and forestry. This study merges terrestrial and aerial Lidar data to evaluate the effectiveness of these tools assessing volumetric changes after a hurricane event of riverbeds and scour bridges The resulted information could be an optimal approach to improve hydrological and hydraulic models, to aid authorities in proper to decision making in construction, urban planning, and homeland security.
\end{abstract}

\section{INTRODUCTION}

Many countries consider prevention and mitigation as the most effective way to reduce the negative consequences of natural disasters. For example, bridge scouring is the number one cause of structural failure ( $\mathrm{Yu}$ and $\mathrm{Yu}, 2011$ ); only in the United States over 1.000 bridges had fallen in a period of 30 years, $60 \%$ are attributed to catastrophic events related to hydrometeorological phenomena and only $2 \%$ to seismic causes (NCHRP, 2003 and Shirole and Holt, 1991). Structural engineers around the world have the task to develop real time bridge scour monitoring systems to evaluate risk management, especially in rivertowns. The strangling of the natural river's flow is a common phenomenon, attributed mostly to the limited hydraulic calculations.

Historical stream banks were wider, but with urbanization and city grow these became narrower. Nevertheless, the actual bridge structure design considers the current width of the rivers. When an intensive flow occurs, rivers regain its original width and the bridge structures stand eroded. Lidar data and its spatial statistics allow a most accurate calculation of volumetric changes at different scale projects (Woodlard and Colby, 2002).

Terrestrial and aerial Lidar data could assess effectively river beds and scour bridges volumetric changes after a hurricane event. This paper proposes the Lidar system as a technological tool to obtain an accurate set of information, which can give a better approach for the creation of Digital Terrain Models (DTM) (Bitelli et al., 2004), land use classification, bridge geoinformation, among many other products that could be used for the National Water Commission or other agencies to solve information deficiencies to improve environmental policies and/or risk management.

The objective of this paper was to create a new $3 \mathrm{D}$ cloud point with the fusion of terrestrial and aerial Lidar data by using different tests of alignment quality between the data and calculating damages using DTM information as well as field work, this to assess damages along highways and bridges in the rivertown.

\section{MATERIALS AND METHODS}

\subsection{Study area and data sets}

The City of Monterrey, also known as the Metropolitan Area of Monterrey (MAM) is located Northeast Mexico and has a total area of $578.3 \mathrm{~km}^{2}$. It is composed of 9 municipalities; six of them affected by the Santa Catarina River (SCR), which crosses the city from West to East, with approximately $58.86 \mathrm{~km}$ line (Figure 1). This type of urban morphology (roads along the river) is a typical case of rivertowns. Historically, the MAM has been affected by hurricanes and the National Weather Service National Oceanic and Atmospheric Administration (NOAA) recorded, from a time period from 1851 to 2008, around 283 storms with wind speeds from 0-196 MPH. The most recent case is hurricane Alex (July 1st, 2010), which collapsed the city's economy for weeks and destroyed the two main highways built parallel to the river. Historical records registered a hurricane in 1909 with a similar hydrological behavior, which also destroyed many of the structures and bridges built at the area back then.

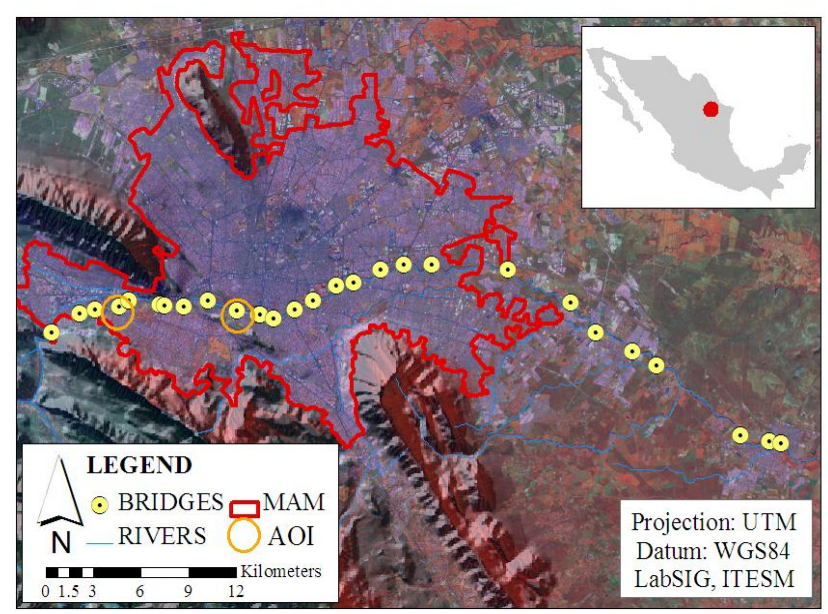

Figure 1. The MAM polygon (background Landsat 5, April $28^{\text {th }}, 2010$ ), showing river study area (blue line), the 25 bridges along the SCR (yellow/black dots) and the sampled areas for the volume calculation tests (circles). 
Hurricane Alex left some places along the SCR in complete devastation. There was an extreme need to reevaluate the hydrological and hydraulic models in order to perform an accurate reconstruction. The catastrophe left 12 mortal victims and expensive rebuilding costs calculated in millions of dollars. This is an example of the urgent need of more complete topographic databases, urban structure monitoring systems and management risk plans, which could allow a better implementation of preventive programs to avoid dramatic consequences.

By 2010 the Santa Catarina River (SCR) which has a very angulated slope (Murillo Sánchez, 2002), had a total of 28 structures along its channel and there was visual evidence (survey pictures, and aerial photography) that many of them represented an obstruction against the natural flow, causing inundations in important areas (Figure 2).

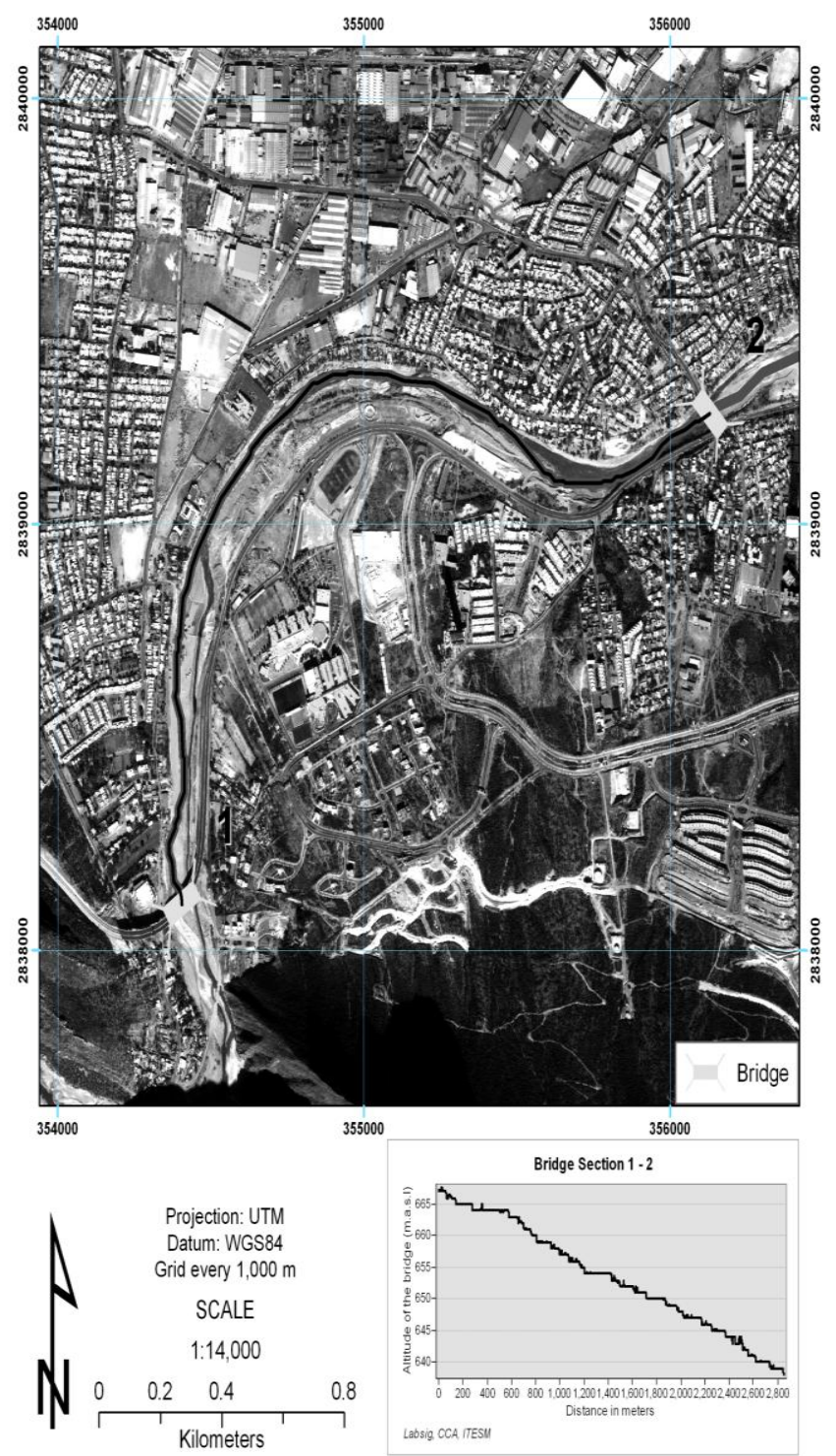

Figure 2. Slope bridge section 1-2, results based on aerial Lidar data.

Although the MAM is the second largest mexican economy; it has many deficiencies such as: 1) indiscriminate change in the land use of the contributor watersheds, having a negative consequence in the loss of natural vegetation cover, decrease of natural infiltration, ground water retention and material drag; 2) lack of geographical information to manage disasters, and 3 ) urban growth disorder.

Terrestrial data: A total of 25 structures along the river were scanned, from October 21th, 2010 to January 21th, 2011, using an ILRIS-3D Intelligent Laser Ranging and Imaging System by Optech Company. Each bridge was considered as an independent data set. Structural characteristics such as size and design were considered in the field to determine the best scan position and angle for each bridge along the SCR. Every scan had an independent measure input, according to the distance and angles calculated in the field, but all of them were programmed searching a resolution quality of $0.05 \pm 0.02 \mathrm{~m}$.

The full data set was georreferenced using control points, located for this specific study, and imported into a GIS based program to manage the information. Geodesic points along the river were taken to give a larger number of global spatial references for each independent bridge. A complementary total station was employed to draw a polygon around the structure using at least 4 GPS points for each bridge, which gave a more accurate reference plane (Figure 3).

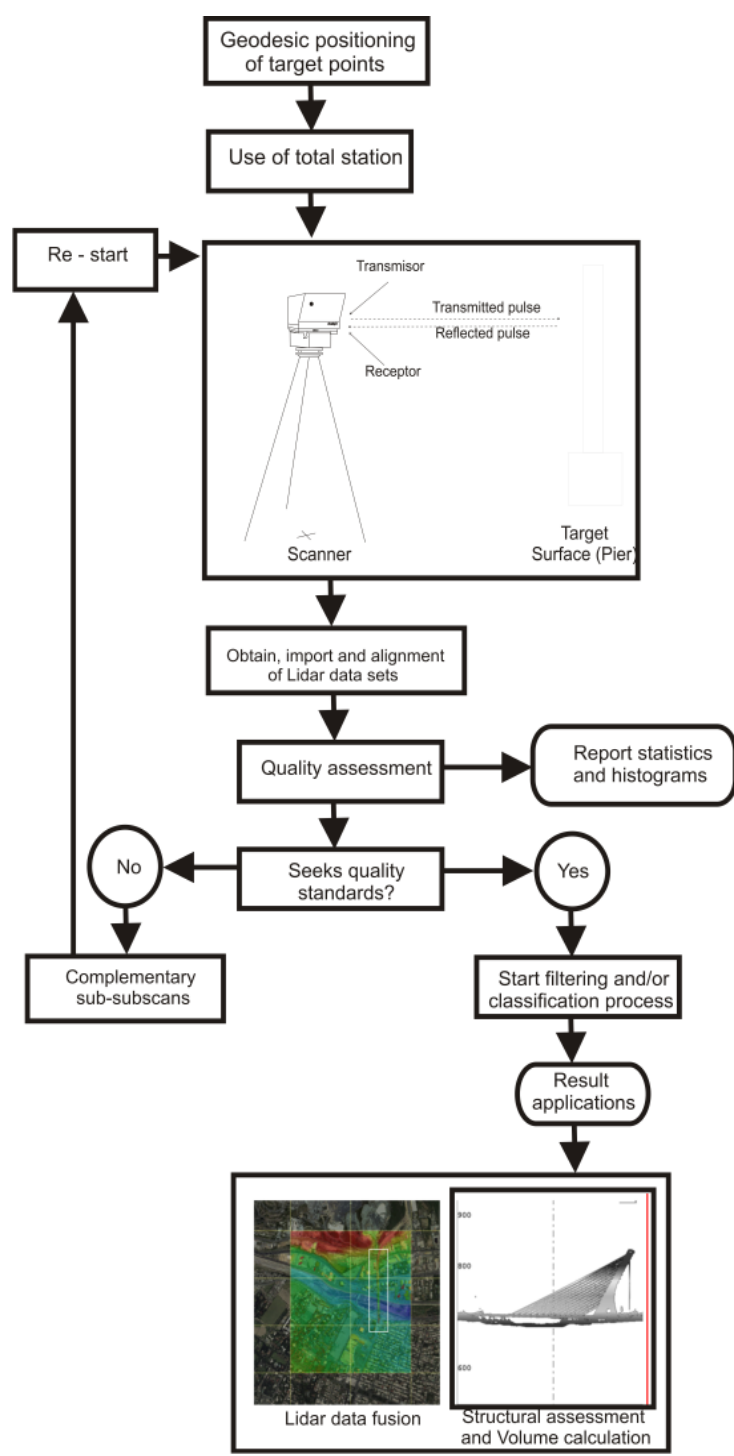

Figure 3. General methodology for terrestrial Lidar data production and fusion. 
Aerial data: An aerial survey was conducted on December 2010 to scan the entire city; the project was supported by the National Water Commission. The survey used an ALS50 Airborne Laser Scanner Phase 2+ from Leica, it provided resolution of $0.70 \mathrm{~m}$ (xy) and $0.15 \mathrm{~m}(\mathrm{z})$. The total scanned area was $202,237.5 \mathrm{~km}^{2}$. The information was filtered using the first return, subdivided in tiles $500 \times 750 \mathrm{~m}$, and exported by areas of interest (one by bridge) covering the complete structure and part of its surrounding environment.

Optical imagery: Two sets of optical images were used: (a) an aerial photography survey by the Instituto Nacional de Estadística y Geografía (INEGI) a week after the hurricane, and (b) a World View 2 Imagery taken on December 2010, almost simultaneous to the aerial Lidar survey. All the aerial photos were rectified using a three order polynomial spatial adjustment corrected from the orthophotography of the MAM from 2007.

\subsection{Data processing: Alignment of the scans / Quality assessment}

Terrestrial data: The information was managed by bridge, and every group of scans were aligned to a common reference plane (Brenner et al., 2007), using composited 3D images, polygonal models, global reference points, huge translation and image alignment technique, which consisted of a least-squares iterative algorithm that automatically refines the approximation, this is called best-fit alignment technique (BFA). The BFA needs to be fed by reference points within tolerance from their original position. This alignment technique allows the combination of BFA technique and known points, marked and measured with a GPS previously.

All the alignment procedure was done using IMAlign module of Polyworks V11 from InnovMetric Software (2011). The alignment quality was also evaluated by statistics and histograms for each 3D Image. The LP360 Viewer Software by QCoherent (2009) was a very useful tool to perform a quick and first evaluation. The information was first converted to LAS format and imported to perform a first visual evaluation of the data. During the first scan, important information of the bridges was missing (parts of the deck, piers or abutment that were in the cutline river) because the angle of vision was blocked. This missing information was complemented with sub-scans in posterior dates.

The bridges' cloud points were filtered and classified using information from the Optech's parser and the optical camera during the scanning process and also from aerial and satellite imagery obtained for the entire project. All bridges were evaluated and subdivided with a qualitative methodology according to the American Association of State Highway and Transportation Officials (AASHTO); and also considering its actual structural condition (Veneziano et. al., 2003 and Khattak et al., 2003). Waterway data needs to be analyzed to determine if deficiencies can be brought into conformance with current standards in a feasible and prudent manner without damaging the bridge's historical value for the city (WSDOT Historic Bridge rehabilitation guidelines). Every bridge was divided as it is shown in Figure 4; highway and slope assessment were done $100 \mathrm{~m}$ after and/or before the bridge, considering affectation due to bridge design.

Methods to correct deficiencies and make historic bridges adequate vary greatly depending on its materials, design and the results of some tests such as (1) analysis of structure condition and waterway adequacy, (2) analysis of load-carrying capacity, (3) analysis of geometry and safety features, and of course (4) an historical and environmental evaluations. Bridges in the study area are primarily composed of plain, reinforced concrete. Common problems for these types of materials are cracking, corrosion which results in spalls, cyclic freezing, shrinkage, creep and/or moisture penetration. The steel structure bridges are also susceptible to rust that could lead to section loss.

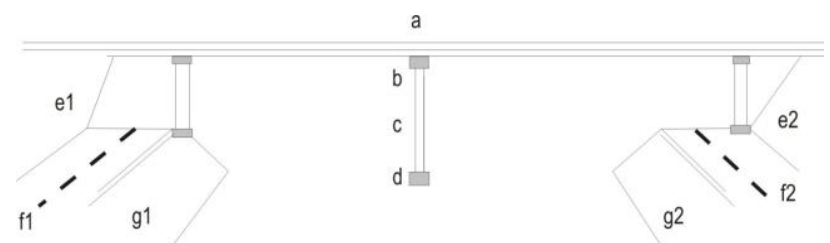

Figure 4. Component parts of the bridge that were evaluated (a) deck, (b) bearing, (c) pier, (d) footing, (e) abutment, (f) highway and (g) slope, number 1 means left side (Constitucion Avenue) and number 2 means right side (Morones Prieto Avenue).

Aerial data: Aerial Lidar data was filtered and classified to obtain bare ground points using some of the filtering techniques available in MARS Software by Merrick \& Company (2010) such as elevation, number of returns, slope and building filters. For field validation we used a World-View2 orthorectified images and aerial photography.

River slope: The slope was calculated using the aerial Lidar data set and the Surface tool script (by Jenness, 2008). This extension allows calculating various surface and topographic characteristics for points, lines or polygons under a GIS frame. The river line was divided by sections between the bridge locations (Figure 2).

Scour volume calculations: As noted, data collection was carried out from October 2010 to April 2011, although during this period many of the river sections were modified, it was possible to do scour volume calculations using a previous Lidar survey done during July and September 2010 for two specific sampled areas.

Terrestrial an aerial data fusion: Both data sets were managed in different ways to be filtered in order to get only the information needed to obtain a DTM (aerial Lidar data) and the bridge structure (terrestrial Lidar data).

\section{RESULTS AND DISCUSSIONS}

This study proved that the erosive track of the hurricane Alex in the assessed area was greater over those places where the design of the bridges strangled the circulation of the natural flow of the channel. The bridges along the river acted as obstructions, 3 of them were removed during the first three days after the event and over $60 \%$ of them presented erosion problems.

The impact of the hurricane Alex in the MAM represents the best example of the risk to this type of events and the vulnerability that population and the infrastructure by itself has in the area; in addition the hurricane modified the river bed and changed its elevation due to sediment transportation, and no plan to monitor the real impact was followed right after. 
Government agencies focused on solving basic needs such as electricity, roads rehabilitation, and attention to victims.

However, geoinformation after a catastrophic event represent invaluable data for the future studies and to assess the real impacts of this type of events at a local scale.

A total of 109 geodesic points were placed covering an area of $11.683 \mathrm{~km}^{2} .159$ scans were needed to cover the 25 bridge structures, averaging 6 scans by Unit Bridge and getting a total of 185 millions of estimated point's data set. Table 1, shows the alignment statistics by bridge. Alignment Standard Deviation ranged on $0.0195 \mathrm{~mm}$ using reference points and BFA techniques having normal distributions. River slope average was $2.11 \%$ calculated using a DTM created with the aerial Lidar information by sections along the $58.86 \mathrm{k} \mathrm{m}$ length of the river study area.

Table 1. Precision scan alignment (SA) statistics by bridge.

\begin{tabular}{lrrr} 
Total bridges & \multicolumn{1}{c}{ Max } & \multicolumn{1}{c}{ Min } & \multicolumn{1}{c}{ Average } \\
\hline Deck (m.a.s.l.) & 690.14 & 324.29 & 502.3611 \\
Slope (\%) & 4.592 & 1.11 & 2.17688 \\
SA Mean & 0.01355 & -0.00311 & 0.000938 \\
SA Std Dev. & 0.03297 & 0.007922 & 0.019458 \\
SA Min & -0.051 & -0.191 & -0.10604 \\
SA Max & 0.191 & 0.036 & 0.10544 \\
\hline
\end{tabular}
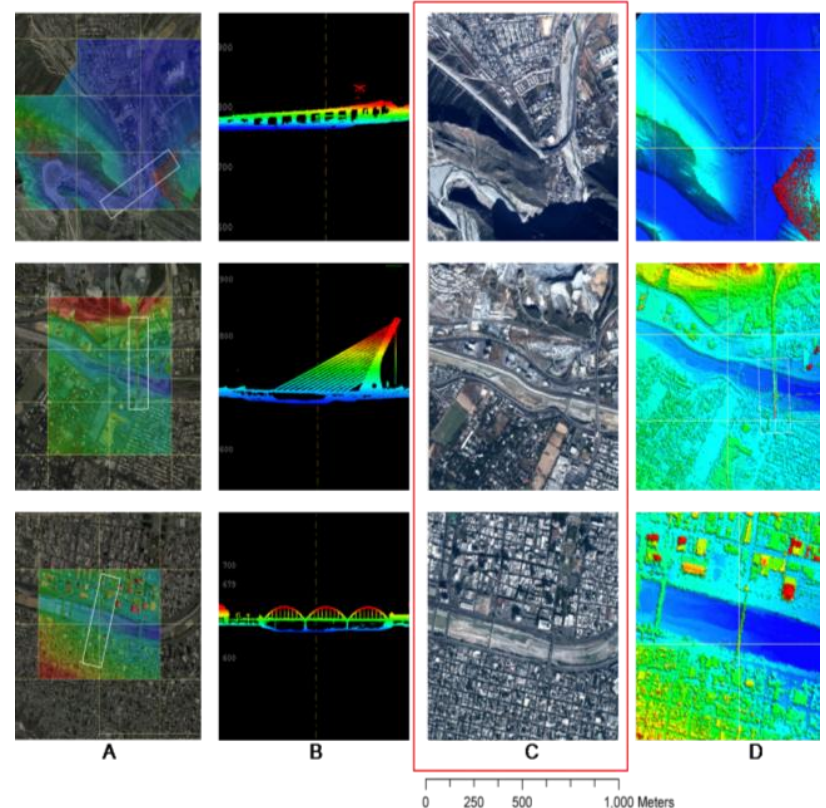

Figure 5. Integration of the two Lidar data sets after the fusion.

Data integration allowed the fusion of terrestrial and Lidar information throughout the area exporting the information to different formats such as LAS or Esri-Ascii. Figure 5 shows the integration of the information in four columns, (A) column shows the fusion of terrestrial and Lidar occurred by exporting the area tiles with direct influence in the bridge, generally were 4 to 6 tiles each and behind an orthophoto, (B) column shows the fusioned data projected in a $-\mathrm{y}$ plane, showing the altitude, (C) column shows the same area in the WorldView 2 imagery and (D) column a TIN integration of Lidar data showing rank color by elevation. The integration of terrestrial data makes possible to have $3 \mathrm{D}$ image information of the bridge substructure.

General river situation after the hurricane is worrying (Table 2). At least $36 \%$ of the left highway and $16 \%$ of the right highway crossing the bridge were collapsed. Slopes attached to bridges (100m up and down river) were highly eroded in a $64 \%$ for the left slopes and $54 \%$ of the right ones.

Visual assessment was done with the three data sets after the hurricane showing a strangled rivertown. Pier and footings presented debris on $16 \%$ of the bridges and at least $20 \%$ of them were eroded or $4 \%$ collapsed. The information to feed the Table 2 was based on field observations and validation on three data sets: (a) photographic field survey done by the general project, (b) a terrestrial Lidar survey, and (c) an aerial survey by INEGI a week after the hurricane.

Table 2. Number of bridges with damage registered using different sources of information.

\begin{tabular}{c|ccccccccc}
\hline \multicolumn{1}{c}{} & \multicolumn{1}{c}{ Abutment } & \multicolumn{3}{c}{ Slope } & \multicolumn{3}{c}{ Highway } \\
\multicolumn{1}{c}{} & $\mathrm{P}$ & $\mathrm{F}$ & $\mathrm{L}$ & $\mathrm{R}$ & $\mathrm{B}$ & $\mathrm{L}$ & $\mathrm{R}$ & $\mathrm{L}$ & $\mathrm{R}$ \\
\hline $\mathrm{C}$ & & & & & & & & $9^{\mathrm{a}}$ & $4^{\mathrm{b}}$ \\
$\mathrm{D}$ & & $1^{\mathrm{a}}$ & & $1^{\mathrm{a}}$ & & & $1^{\mathrm{b}}$ & $2^{\mathrm{a}}$ & $4^{\mathrm{a}}$ \\
DP \& NVD & $1^{\mathrm{a}}$ & $3^{\mathrm{a}}$ & $1^{\mathrm{b}}$ & & & $1^{\mathrm{c}}$ & & & \\
E & $4^{\mathrm{b}}$ & $4^{\mathrm{b}}$ & $2^{\mathrm{a}}$ & $1^{\mathrm{b}}$ & & & & & \\
NVD & $1^{\mathrm{a}}$ & $14^{\mathrm{b}}$ & 2 & $1 \mathrm{~b}$ & $15^{\mathrm{c}}$ & $2^{\mathrm{b}}$ & 2 & $10^{\mathrm{a}}$ & $12^{\mathrm{a}}$ \\
SNE & $18^{\mathrm{b}}$ & 1 & $22^{\mathrm{b}}$ & $21^{\mathrm{a}}$ & $9^{\mathrm{a}}$ & $3^{\mathrm{a}}$ & $6^{\mathrm{a}}$ & 4 & 5 \\
HE & 1 & $1^{\mathrm{a}}$ & 1 & 1 & & 3 & 3 & & \\
DP\&E & & $1^{\mathrm{c}}$ & & & $1^{\mathrm{b}}$ & $16^{\mathrm{b}}$ & $13^{\mathrm{c}}$ & & \\
\hline
\end{tabular}

Nomenclature as follows: Bridges with no visible damage (NVD), damaged (D), eroded (E), high erosion (HE), collapsed (C), debris present (DP), structure not existent (SNE), pier (P), footing (F), left (L) and right $(\mathrm{R})$ sections and bed (B). Data based on: (a) photographic field survey done by the general project, (b) a terrestrial Lidar survey, and (c) an aerial survey by INEGI.

The first sampled area $\left(1,683 \mathrm{~m}^{2}\right)$ was a pier and footing section of Bridge 14 (Figure $6 \mathrm{a})$. The second sampled area $\left(9,500 \mathrm{~m}^{2}\right)$ on a $300 \mathrm{~m}$ section from the right margin highway (Morones Prieto Avenue) between the Bridge 4 and Bridge 5 (Figure 6f). Scour bridge calculations were done only for the two sampled areas (1) nose section of a pier and footing of the Bridge 14 and (2) a section of the right highway between Bridge 4 and Bridge 5. A TIN volume calculation was done with a reference plane over the river bed and using the dimensions of the original road or pier. Bridge 4 (locally known as Guadalupe Bridge) has an elevation around 503 m.a.s.l., which presented scour on some piers, footing, and abutment (Figures $6 \mathrm{~b}$ and $6 \mathrm{c}$ ). The most damaged pier was sampled taken an area of $480 \mathrm{~m}^{2}$ from the footing.

Results showed a local scour pier volume of 2,505 $\mathrm{m}^{3}$ (Table 3) only for the area sampled (Figure $6 \mathrm{c}$ and $6 \mathrm{~d}$ ). After some weeks, the reconstruction started and the section was completely modified (Figure 6e), because it represents one of the first two main highways for the city. The dependency of the city over this road determined to reconstruct over the same conditions, and three months after the highway was rebuilt in the same place. 


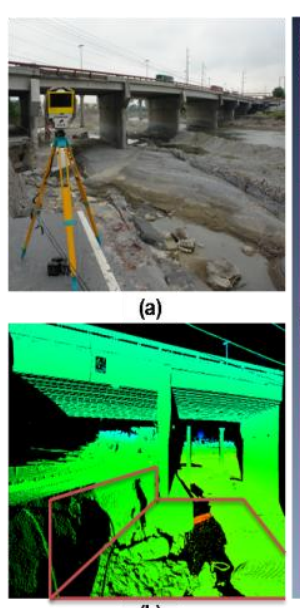

(b)

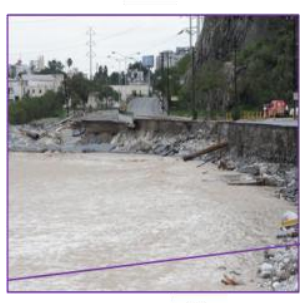

(f)

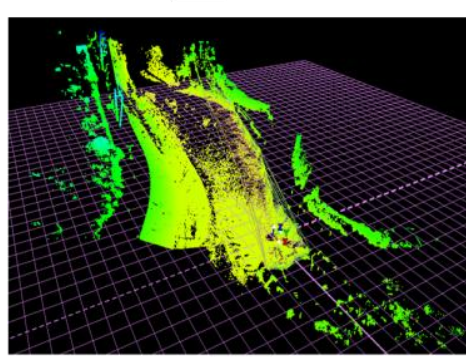

(h)

(c)
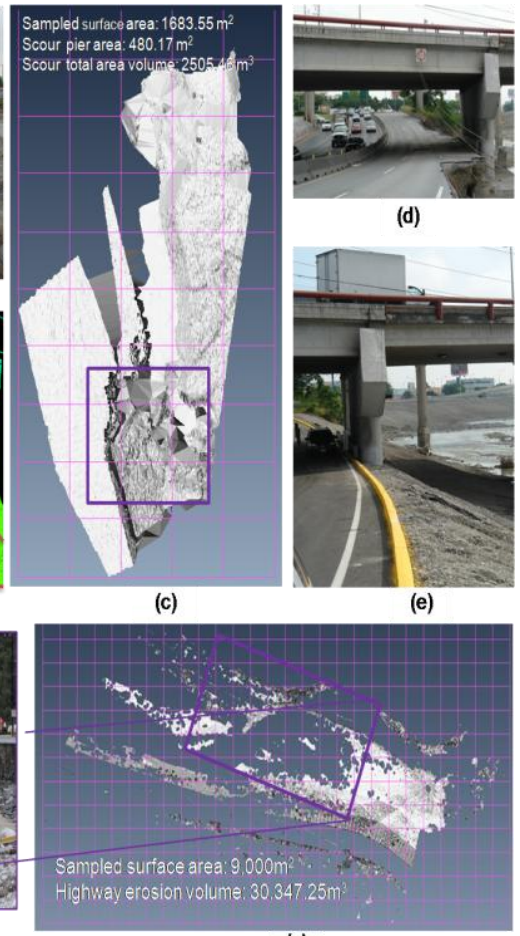

(g)

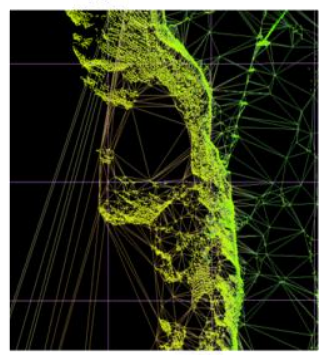

(i)

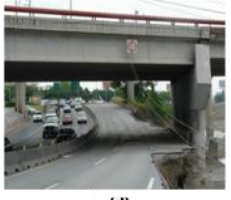

(d)

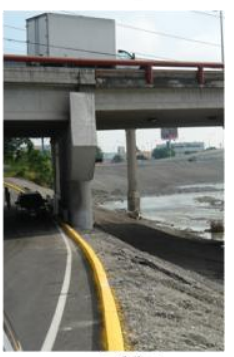

(e)
Figure 6. Volume calculations for Bridge 4: (a) scanning process, (b) data management, (c) volume calculations, (d) traffic, and (e) area location rebuilt; and the $300 \mathrm{~m}$ highway section between the Bridge 4 and Bridge 5: (f) highway section, (g) data management, (h) volume calculations, (i) zoom in on the sampled area triangulation process.

Table 3. Total scour area and volume results of the assessment.

\begin{tabular}{|c|c|c|c|}
\hline Measurement & Area $\mathrm{m}^{2}$ & Volume $\mathrm{m}^{3}$ & Notes \\
\hline \multicolumn{4}{|l|}{ First area sampled } \\
\hline Before hurricane $^{a}$ & $1,700.50$ & $6,911.34$ & \multirow{4}{*}{$\begin{array}{l}\text { Pier and } \\
\text { footing } \\
\text { damages }\end{array}$} \\
\hline After hurricane ${ }^{b}$ & $1,220.33$ & $2,505.46$ & \\
\hline After reconstruction $^{c}$ & $1,860.90$ & $6,802.00$ & \\
\hline Total scour & 480.17 & $4,405.88$ & \\
\hline \multicolumn{4}{|l|}{ Second area sampled } \\
\hline Before hurricane ${ }^{a}$ & $9,300.50$ & $37,800.00$ & Highway \\
\hline After hurricane ${ }^{b}$ & $2,494.97$ & $7,452.61$ & damages \\
\hline After reconstruction $^{c}$ & $9,500.00$ & $38,000.00$ & \\
\hline Total scour & $6,805.53$ & $30,347.39$ & \\
\hline
\end{tabular}

Note: (a) Lidar survey from INEGI, 2007, (b) a terrestrial Lidar survey one week after the hurricane, and (c) an aerial survey from the National Water Commission on December 2010 (five months after the hurricane).

Using the same methodology above the 3D information was managed for the first and second sampled area of $9,000 \mathrm{~m}^{2}$, resulting in a highway volume erosion of $30,347 \mathrm{~m}^{3}$. This section was also reconstructed two months after the hurricane with the same dimensions (Table 3).

\section{CONCLUSIONS AND RECOMMENDATIONS FOR FUTURE WORK}

Aerial Lidar data is one of the most effective and reliable set of information that can be collected to measure topography. However, general idea is that the more accurate and precise data, the higher cost to obtain and store it. It can be very difficult to obtain and require larger databases. For this reason, it is important to know the objectives of the study before choosing the type of Lidar system. The general idea is not necessarily correct.

For example $0.05 \mathrm{~m}$ terrestrial Lidar data will cost more to collect (in terms of area collected) than aerial Lidar data $(\sim 0.70 \mathrm{~m}$ resolution), but if it's necessary to have the entire city information it's more cost effective to perform an aerial Lidar survey. However, a smaller project area could be more cost effective with terrestrial Lidar data if the objective seeks higher accuracy and smaller precision errors.

This paper demonstrates that terrestrial and aerial Lidar data are complementary; the fusion of both data sets was very useful in terms of assessing hydrometeorological impacts on bridge structures, slopes and highways along the river.

Optical imagery and terrestrial Lidar data was very useful data for validation, giving important information for reconstruction processes (Impyeong and Yunsoo, 2004); however a complete photographic survey right after a hurricane event must be always necessary and very useful in terms of evidence of tracking erosive damage.

An important issue over the study area was the reaction of the State and Federal authorities after the hurricane, reconstruct the highways and slopes as soon as possible was their first reaction, and the majority of them were rebuilt exactly in the same places and dimensions.

This shows the lack of information and understanding of the consequences of their actions as part of the risk of population and infrastructure. However, without a real geographical database and a monitoring system for bridge stage will be difficult to make up the right policies and a risk management plan for the MAM.

There is an urgent need of geoinformation that could help to understand and reevaluate the hydraulic capacities of river flows. The feasibility to use terrestrial Lidar and its fusion with aerial Lidar has demonstrated the real track impact of the river erosion after a hurricane event and the feasibility for volumetric assessment drawing up dimensions and other specific measures needed as an important issue for future hydraulic bridge calculations.

\section{REFERENCES}

Bitelli, G., M. Dubbini and A. Zanutta, 2004. Terrestrial laser scanning and digital photogrammetry techniques to monitor landslide bodies. Proceedings of Commission V, XXth ISPRS Congress, 12-23 July 2004, Instanbul, Turkey, pp. 246-251. 
Brenner, C., C. Dold and N. Ripperda, 2007. Coarse orientation of terrestrial laser scans in urban environments, Journal of Photogrammetry and Remote Sensing, 63(1):4-18.

Impyeong, L. and C. Yunsoo. 2004. Fusion of terrestrial laser scanner data and images for building reconstruction. Proceedings of Commission V, XXth ISPRS Congress, 12-23 July 2004, Instanbul, Turkey, p.6.

Jenness, J., 2008. Surface Tools (surf_tools.avx) extension for ArcView 3.x, v. 1.6a. Jenness Enterprises. URL: http://www.jennessent.com/arcview/surface_tools.htm, Flagstaff, Arizona (last date accessed: 31 May 2011).

Khattak, A. J., S. Hallmark and R. Souleyrette, 2003. Application of light detection and ranging technology to highway safety, Transportation Research Record: Journal of the Transportation Research Board of the National Academies, 1836(2):7-15.

Murillo Sánchez, E., 2002. Estudio del efecto del cambio de uso de suelo en el escurrimiento en la subcuenca 24Bf "Monterrey", aplicando un sistema de información geográfica, M.Sc. Thesis, Instituto Tecnológico y de Estudios Superiores de Monterrey, Monterrey, Nuevo León, $119 \mathrm{p}$.

National Oceanic and Atmospheric Administration, 2010. Historical hurricane tracks. URL: http://csc.noaa.gov/hurricanes/\#, NOAA/National Weather Service, National Centers for Environmental Prediction, National Hurricane Center, Miami, Florida (last date accessed: 14 May 2010).

Shirole, A.M., and R.C Holt, 1991. Planning for a comprehensive bridge safety assurance program, Third Bridge Engineering Conference, Transport Research Record 1290 Volume 1, 10-13 March 1991, Denver, Colorado, pp. 39-50.

Veneziano, D., R. Souleyrette and S. Hallmark, 2003. Integration of light detection and ranging technology with photogrammetry in highway location and design, Transportation Research Record: Journal of the Transportation Research Board of the National Academies, 1836(1):1-6.

Woodlard, J.W. and J. D. Colby, 2002. Spatial characterization, resolution, and volumetric change of coastal dunes using airborne Lidar: Cape Hatteras, North Carolina, Geomorphology, 48(1): 269-287.

$\mathrm{Yu}, \mathrm{X}$. and $\mathrm{X}$. Yu, 2011. Assessment of an automation algorithm for TDR bridge scour monitoring system, Advances in Structural Engineering, 14(1):13-24. 